\title{
The effect of age on language in adults with intellectual disabilities: A comparison of passives in Down syndrome and Williams syndrome
}

\author{
Alexandra Perovic ${ }^{1} \cdot$ Ken Wexler $^{2}$ \\ 'University College London, UK, Division of Psychology and Language Sciences, Department of \\ Linguistics and ${ }^{2}$ Massachusetts Institute of Technology, USA, Department of Brain and Cognitive \\ Sciences, Department of Linguistics
}

https://doi.org/10.17234/9789531758314.03

\begin{abstract}
Individuals with intellectual disabilities often show limitations in language functioning, commonly linked to their overall poor cognitive skills. However, despite the intellectual impairments and language delays, it is well established that language is more vulnerable in some populations, e.g. Down syndrome (DS), and relatively preserved in others, e.g. Williams syndrome (WS). Individuals with DS are also known to be at increased risk of cognitive decline due to the earlier onset of Alzheimer's dementia, although little is known about how aging affects language skills in this population. Individuals with WS, though with relatively developed language, are reported to never acquire some grammatical structures that appear late in typically developing (TD) individuals, such as passives of psychological verbs.

In an attempt to better understand how linguistic deficits in individuals with intellectual disabilities can be teased apart from the effects of general language delays, chronological age, and overall intellectual impairment, we compare the comprehension of passives in adults with DS (mean age: 38 ) and WS (mean age: 30 ). Passives are known to develop late in typical development and present difficulties for individuals with developmental disorders. This has been observed especially in their generally poorer performance on passives of psychological verbs than on passives of actional verbs.

Our results reveal divergent patterns of performance in our participants. Adults with WS performed no different from younger TD controls on actives and passives of both actional and psychological verbs. In contrast, adults with DS showed exceptionally poor performance on all sentence types, even on actives of actional verbs, considerably poorer than observed in the TD and WS groups. While the good performance of adults with WS might be due to individual variation, rather than continuous language development, we argue that the poor performance of participants with DS is due to an age-related decline of cognitive and language abilities, possibly linked to Alzheimer's-type dementia.
\end{abstract}




\section{Introduction}

Individuals with intellectual disabilities (IDs) by definition have significant limitations in intellectual functioning (i.e. reasoning, planning, solving problems, thinking abstractly, comprehending complex ideas, learning quickly, and learning from experience) and in adaptive behavior expressed in conceptual, social, and practical skills that originate before the age of 18 (AAIDD, 2010). Limitations in language functioning are not specifically noted in this definition; however, most individuals with IDs will have some language difficulties. This may be in the domain of vocabulary, where they may not be able to comprehend abstract terminology or appropriately express their thoughts and intentions; in the domain of phonology, where they may not be able to pronounce certain consonant clusters, making their speech unintelligible to others; in the domain of grammar, where they may not be able to rely on grammatical devices to mark the time or a duration of an event that has happened; in the domain of pragmatics, where they may not be able to use linguistic devices to specify referents involved in an event, or in the domain of semantics, where they may not comprehend subtle ambiguities in meaning. Limited competence in any of these domains may considerably affect these people's adaptive functioning, independent of intellectual skills such as planning or reasoning.

The question that has long intrigued researchers is whether a depressed level of language ability should be interpreted as a result of poor intellectual ability. However, the wide variability in both language and intellectual functioning of individuals with IDs makes this premise almost untestable. Still, it is well established that language is more vulnerable in some populations than in others, and while language is typically delayed in many populations, their ultimate linguistic achievement can be very different. Furthermore, it is now accepted that individuals with IDs rarely show flat profiles in their cognitive or language abilities: we see strengths and weaknesses in different domains. For instance, in Williams syndrome, visuo-spatial abilities can be severely affected, while verbal shortterm memory is relatively spared (Mervis, 2006). In Down syndrome, verbal short-term memory is known to be severely deficient, and visuo-spatial abilities relatively strong (Abbeduto, Warren \& Conners, 2007). It is also now known that some populations experience a decline in their cognitive skills as they age: individuals with Down syndrome are at an increased risk for Alzheimer's disease and show a tendency toward accelerated biological aging (e.g. Zigman \& Lott, 2007). However, it is unclear how aging affects language skills in individuals with Down syndrome: some studies report a decline in language skills from around 40 years of age (e.g. Carter Young \& Cramer, 1991), while others find no evidence for such a decline (e.g. Devenny \& Krinsky-McHale, 1998; see Witecy \& Penke, 2017, for a recent review). 
In an attempt to better understand whether, and how, linguistic deficits in individuals with IDs can be teased apart from the effects of overall intellectual impairment and general language delays, here we compare the linguistic competence of two populations that have often been compared in the literature: Down syndrome (DS) and Williams syndrome (WS). They are etiologically distinct developmental disorders with distinct cognitive and language profiles, but language delays and IDs are common to both. In order to avoid the effects of language delay and differential rates of development, we focus on adults, whose language development is unquestionably complete, but, crucially, may now be subject to decline, at least in DS.

In the ensuing sections, we give an overview of the cognitive and language skills of individuals with WS and DS before presenting our small-scale study involving adults with these disorders. We focus on assessing the comprehension of passives, an aspect of grammar known to develop late in typically developing (TD) children and also to present difficulties for individuals with language and cognitive impairments.

\section{Language and cognition in DS vs. WS}

WS is a rare genetic disorder caused by the deletion of about 26 genes on the long arm of chromosome 7, affecting between 1 in 7,500 and 1 in 25,000 individuals (Ewart et al. 1993). The deletion of the crucial gene, Elastin, is associated with a number of medical conditions and a specific cognitive profile (see Royston, White \& Howlin, 2019 for a review). Disparities are noted between different aspects of cognitive abilities: visuo-spatial construction skills may be particularly affected, along with sensory motor processing, executive function, and attention. Auditory memory, however, is relatively preserved (Mervis, 2006). WS has been hailed as an example of intact language and impaired cognition (Bellugi, Marks, Bihrle \& Sabo, 1988). However, it is now accepted that the language of individuals with WS, while not intact, is a relative strength compared to other aspects of cognition affected by the syndrome (cf. Mervis, 2006). A number of studies have shown a command of various aspects of grammar at levels comparable to those in younger TD children functioning at equivalent levels of cognitive and verbal functioning: binding (Ring \& Clahsen, 2005, Perovic \& Wexler, 2007; 2018), passives of actional/agentive verbs (Clahsen \& Almazan, 1998; Ring \& Clahsen, 2005; Perovic \& Wexler, 2006; 2010), wh-questions and relative clauses (Zukowski, 2001). However, there are indications that aspects of complex grammar known to develop late in typical populations (e.g. raising, Perovic \& Wexler, 2007; passives of psychological verbs, Perovic \& Wexler, 2010) may be further delayed or even unattainable. 
DS is a chromosomal disorder caused by trisomy of chromosome 21. Affecting about 1 in 650-1000 live births worldwide (Bittles, Bower, Hussain \& Glasson, 2007), it is one of the most common causes of ID. It is associated with significant health issues, hearing loss, and premature aging. It has long been known that individuals with DS over the age of 35-40 show neuropathological hallmarks of Alzheimer's disease (Malamud, 1972), such as amyloid plaques and neurofibrillary tangles. The role of chromosome 21 is crucial, as it contains a number of genes implicated in Alzheimer's, thus putting individuals with DS at particular risk, compared with individuals with other IDs (Lott \& Dierssen, 2010). However, definitive signs of dementia do not appear until later, and it is unclear whether dementia presents differently in DS compared to the types of Alzheimer's dementia that appear in typical populations (e.g. Zigman \& Lott, 2007; Zis \& Strydom, 2018).

The cognitive profile of DS is characterized by disparities between different domains: impairments in auditory memory, attention, and executive function are common, but visuo-spatial abilities are typically less impaired, for instance (Abedduto et al, 2007). Language in DS has been reported to be more noticeably affected than cognitive abilities, which sets it apart from other populations with IDs (Perovic, 2006; Abedduto et al, 2007). There is, of course, wide individual variation in both language and intellectual abilities among people with DS (Karmiloff-Smith, Al-Janabi, D'Souza et al, 2016). However, disparities between measures of overall mental age (MA) and language measures have been reported in both children and adults with DS (e.g. Fowler, Gelman \& Gleitman, 1994; Rondal \& Comblain, 1996). This is most obvious in their command of morphosyntax. ${ }^{1}$ Chapman, Seung, Schwartz \& Kay-Raining Bird (1998) report that expressive language of 5 - to 8 -year-old children with DS, measured by mean length of utterance (MLU), was comparable to a TD 2-year-old child, while the MLU of adolescents (16- to 20-year-olds) was comparable to that of a TD 3-yearold child. Even if MLU improved in adolescence, grammatical morphology remained deficient. The results of these and numerous other studies bring into focus dissociations at the level of the language faculty itself: aspects of language functioning that seem most impaired in this population are those of the computational system, i.e. morphosyntax and phonology, in contrast to those associated with the general processing system, i.e. vocabulary and pragmatics. Studies typically show impairment in any of the areas of grammar studied (with the focus on English-speaking individuals): binding (Perovic 2001; 2006, Ring \& Clahsen, 2005), passives of actional verbs (Bridges \& Smith, 1984; Ring \& Clahsen 2005; Joffe \& Varlokosta, 2007), wh-questions (Joffe \& Varlokosta, 2007).

1 There is evidence, however, that DS children's morphosyntactic abilities as measured in production studies are obscured by their very poor phonological abilities. See Christodoulou (2015), Christodoulou and Wexler (2016). 
The effect of aging and possibly Alzheimer's disease on language abilities in DS has not been systematically investigated, despite interesting overlapping in the linguistic profiles. Research on Alzheimer's dementia in typical adults has uncovered a range of linguistic deficits, usually linked to impaired working memory. Semantic impairments are most commonly reported (e.g. Altmann \& McClung, 2008), in addition to impairments in sentence comprehension (e.g. Rochon, Waters \& Caplan, 2000) and production (e.g. Altmann, 2004). Crucially, grammatical difficulties are observed in both spontaneous speech and in experimental tasks, in the production of passives (e.g. Bates, Marchman, Harris, Wulfeck \& Kritchevski, 1995), subject-verb agreement, and the production of closed-class words (auxiliaries, determiners, prepositions) (e.g. Altmann, Kempler \& Anderson, 2001; though see Kavé, 2003), which are also typically impaired in individuals with DS.

Early studies investigating effects of age on language in DS seldom used methods common in the dementia research reviewed above: they either relied on proxy measures, such as reports by carers of individuals with DS (e.g. Carter Young \& Kramer, 1991), or they focused on verbal IQ subscales, which usually assess receptive vocabulary only (e.g. Devenny \& Krinsky-McHale, 1998), the aspect of language abilities that we know is often the strongest in individuals with DS. One study that focuses on pragmatic aspects of language functioning, however, does report a decline in these language skills. Relying on a behavioral checklist administered to caregivers of adults with DS, Nelson, Orme, Osann \& Lott (2001) report problems in social conversational style, failure to grasp the meaning of spoken or written words, and difficulty interacting with others in those 40-year-olds with DS with confirmed neurological and MRI changes. This study also reports a decline in vocabulary comprehension, as measured by the Peabody Picture Vocabulary Scales, though grammatical abilities were not assessed.

The few studies that have investigated language skills in more detail report divergent results. Rondal \& Comblain (1996) and Witecy \& Penke (2017) report no age-related changes in cross-sectional studies of grammar comprehension in French and German children and adults with DS, respectively. Witecy and Penke's (2017) results on the comprehension of a range of sentences presented in the German version of the Test of Reception of Grammar (TROG) reveal difficulties with grammar typical of DS, with some of their participants (the younger group was aged $4 ; 6-19 ; 0$; the older group, $20 ; 8-40 ; 3$ ) unable to comprehend even simple sentences. Yet some studies report improvement with age in aspects of phonology, semantics, and grammar in German (Schaner \& Wolles, 2004) and in Greek (Sanoudaki \& Varlokosta, 2015). However, except for Rondal \& Comblain, these studies do not include adults with DS over the age of 40 , when 
signs of dementia are more likely to appear in this population, and do not include assessments designed to assess for presence of dementia.

Iacono, Torr \& Wong (2010) included assessments of dementia as well as measures of receptive and expressive language in a large sample of 55 adults with DS in the relevant age range: $19-55$ years. Once the data of ten of their participants, aged 39-58, with confirmed or suspected diagnoses of Alzheimer's dementia was removed, their analysis showed no age-related decline in receptive language, measured by a standardized test of vocabulary, morphology, and syntax, but pointed to a significant decline in expressive language, as measured by MLU. Note, however, that MLU is not a reliable measure of morphosyntax - a higher MLU does not automatically mean a more sophisticated use of grammatical morphemes in an individual whose vocabulary production may be more advanced than their grammar. Also, this study does not report their participants' results on the linguistic structures tested in the standardized measure of receptive morphology and syntax, making comparisons to other studies difficult.

\subsection{Passives and their acquisition in typical development, Down syndrome, and Williams syndrome}

The verbal passive ('Mary is kissed by John') is a construction known to pose difficulties for both TD children and those with developmental disorders. However, the comprehension of verbal passives is known to be affected by the type of verb used: children as young as four perform well on passives of actional/agentive verbs (e.g. kiss, push), whereas passives of psychological verbs (e.g. see, love, also referred to as non-actional and experiencer verbs) are difficult to comprehend even for 7-year-olds (e.g. Maratsos, Fox, Becker, \& Chalkley, 1985). One wellknown explanation for this pattern of performance is that it reveals an incomplete knowledge of the syntactic movement involved in the formation of passive (Borer \& Wexler, 1987). These authors argue that children's good performance on passives of actional verbs is due to a particular strategy of interpreting these structures as adjectival passives. Adjectival passives (e.g. The door is broken) are distinct from verbal passives: they are formed independently of the syntactic mechanism needed for the formation of the verbal passive (see Hirsch \& Wexler, 2006, for a review of studies on typical development, Perovic \& Wexler, 2010, for a review on studies on atypical development, and Wexler, 2004, for a detailed theoretical advancement of his theory).

There is little systematic research investigating the full range of passive constructions in individuals with DS, which includes both actional and psychological verbs, the latter being a means of testing the full knowledge of passives in the literature on typical acquisition. 
In the very first study on this topic, Bridges \& Smith (1984) used an actout task to test actives and long (long: including the 'by-phrase') get passives in 24 participants with DS, age range: $4-17$. They report scores of between $70 \%$ and $100 \%$ on actives, and only between $30 \%$ and $50 \%$ on the passives, comparable to TD 4-year-olds. Since get passives have characteristics of adjectival passives, and young children do much better on get than be passives, this poor performance is consistent with what we know about DS children not being able to use the adjectival interpretation to comprehend be verbal passives.

Bellugi, Bihrle, Jernigan, Trauner and Doherty (1990) report data from one of the first comparisons of language and cognitive abilities in DS and WS. Six adolescents in each group (mean age: DS group $=15 ; 4$; WS group $=14 ; 4$ ), matched on age and full IQ, showed a distinct pattern of performance: on long passives of actional verbs, participants with WS averaged about $90 \%$ correct, while those with DS performed at chance.

Clahsen \& Almazan (1998) and Ring \& Clahsen (2005) used a four-picture selection task to test comprehension of passives of actional verbs only, both short (without the 'by-phrase') and long, in teenagers with DS and WS, and in MA-matched younger controls. Participants with DS performed at chance on long and short passives, and just under $80 \%$ correct on actional actives. Participants with WS performed considerably better, with $90 \%$ correct on actives, and around $80 \%$ on long and short passives. Different patterns, however, were observed on the same task in Joffe \& Varlokosta (2007) in the performance of younger children with WS and DS (aged 6-14, mean=8;9), compared to much younger MA-matched TD controls (aged 3;3-6;5, mean=4;4). Groups with WS and DS performed equally poorly overall, significantly worse than TD controls, but not significantly different from each other. All groups performed poorly on passives, though a surprisingly low performance on actives was recorded for all the participant groups: 55\%, 64\%, and $74 \%$ correct, for DS, WS, and TD, respectively, indicating that the task may have been too demanding even for the TD controls. Witecy and Penke (2017), mentioned in the previous section, also report chance performance of their child and adult participants on the four actional long passives tested in the German version of the standardized grammar comprehension test, TROG.

Eriks-Brophy, Goodluck \& Stojanovic (2004) was the only study that tested both actional and psychological verbs in DS. Their participants were 8 individuals with DS aged 11-33, with vocabulary skills higher than usual on the scale (vocabulary age equivalent ranging between 6 and 12;11), prompting the authors to label them as high-functioning, although no IQ scores were reported. Two tasks were used to assess the comprehension of passives, act-out and Truth-Value-Judgment (TVJ), with 4 tokens of each construction: 2 'false'; 2 'true'. The participants' performance on actional actives was very good, at $97 \%$ and $84 \%$ 
correct in the act-out task and the TVJ task, respectively. Their performance on long actional passives was considerably poorer, at $59 \%$ and $66 \%$ correct, and on long non-actional passives even poorer, at $41 \%$ and $34 \%$ correct. There was a disparity, however, in their performance on short non-actional passives on the act-out task, at $47 \%$, vs. the considerably higher $85 \%$ on the TVJ task. The participants' performance on actives of non-actional verbs was $78 \%$ correct on the act-out task, and only $62 \%$ correct for the TVJ task. The poorer performance on the TVJ task could be explained by task effects: the task involved somewhat complicated and long stories, that were likely highly demanding on the participants' memory and inferencing skills, but since no comparison data are available from TD controls, it is difficult to interpret these results.

In addition to the studies above, which included comparisons of children with WS and DS, and only passives of actional verbs, two studies investigated passives of both actional and psychological verbs in WS. Karmiloff-Smith, Tyler, Voice, Sims, Udwin, Howlin \& Davies (1998) tested comprehension of long but not short passives of psychological and actional verbs in eight teenagers and adults with WS, aged 14;9-4;8 (mean age $=20 ; 7$ ). The authors report a 17-percent error rate on actives of actional verbs, a 17 percent error rate on passives of actional verbs, and a 33-percent error rate on actives and passives of psychological verbs combined. No breakdown of scores for actives and passives of psychological verbs is given however, and no details of the task and the verbs used, again making these results difficult to interpret.

Perovic \& Wexler (2010) carried out the most comprehensive study of passives in WS to date, involving 26 children and teenagers with WS, aged 6-16 (mean age $=11 ; 6$ ), and three groups of TD controls, matched separately on different measures of language and non-verbal reasoning to the WS group. Actives of actional and psychological verbs, and short and long passives of actional and psychological verbs were tested relying on a picture-selection task - the methodology used in the majority of studies reviewed previously - which was developed and used in one of the largest studies on passives in typical development, that of Hirsch \& Wexler (2006). The results show a strong performance on actives and actional short and long passives in the WS group, no different from three TD control groups. However, their performance on passives of psychological verbs, both long and short, was extremely poor, and significantly worse than any of the TD control groups': only 18 percent correct for PLP, and 33 percent correct for PSP. Interestingly, 5 out of 26 children with WS in this sample performed well on passives of both actional and psychological verbs. These children did not perform unusually well on the standardized measure of language and cognition; however, they were among the oldest in the sample: aged 12, 13, 14;4, 15 , and $16 ; 6$. Note that there were an additional 8 children in the sample aged 12 and above who did not perform well on psychological passives; and none 
of the younger children showed good performance on psychological passives (though they may have done so on actional passives). It is unclear whether this is a simple instance of individual variation, or whether age has some role to play in these teenagers' better command of passives, a point we shall come back to in the Discussion.

\subsection{The current study}

To investigate the full range of passives in two distinct types of IDs as well as the possible effects of age on the mastery of this complex syntactic structure, the current study focuses on the comprehension of passives in adults with DS vs. in adults with WS, relying on the methodology widely used in the literature with both typically and atypically developing populations to minimize task effects.

For DS, we predict poor performance on psychological passives (these passives being the means of testing the knowledge of passives in the TD population), based on two points: (a) the well-known syntactic deficits in the population with DS, and (b) the cognitive decline attributed to early Alzheimer's dementia in adults with DS over the age of 35, which may also cause a decline in language abilities. Both (a) and (b) predict poor performance on both actional and psychological passives. However, only (b) predicts poor performance on active sentences too, regardless of the verb.

For WS, we predict good performance on passives of actional verbs, and a poorer performance on psychological passives, in line with the results reported in the literature, and the reasonable hypothesis that children with WS (but not those with DS) are able to substitute the adjectival interpretation for the verbal passives for actional verbs. However, based on the individual variation reported for teenagers with WS in Perovic \& Wexler (2010), it is also possible that some of our adults with WS may perform relatively well on passives of psychological verbs.

\section{Experiment \\ 3.1 Participants}

Six adults (two males) with DS, aged 24-47 (mean: 38), six adults with WS (two males), aged 19-43 (mean: 30), and six TD children (two males) aged 4-5;9 (mean: 4;6) were included in the study. The participants with DS were recruited and tested in London, United Kingdom, with the help of the charity Choice Support. The participants with WS and the TD controls were recruited as part of a larger study in the United States, with the help of the Williams Syndrome 
Foundation. ${ }^{2}$ Adults with WS all lived at home with their families, while adults with DS lived in supported housing, without their families.

Table 1 gives the participants' results on standardized assessments of verbal and non-verbal skills. The adults with DS and the TD controls were matched on the raw score of KBIT Matrices, a measure of non-verbal reasoning ( $\mathrm{p}=.348$ ). The groups with WS and DS were matched on chronological age only; despite the group with DS being 8 years older on average, this difference was not statistically significant $(\mathrm{p}=.125)$. These two groups could not be matched on any of the language or intellectual functioning measures, due to the floor effects in the scores of participants with DS on all the standardized measures (see Table 1). All groups were matched on gender.

Table 1. Participants' characteristics

\begin{tabular}{|l|r|r|r|}
\hline \multicolumn{1}{|c|}{ Group } & DS & \multicolumn{1}{c|}{ TD } & \multicolumn{1}{c|}{ WS } \\
\hline Mean Age in years & $38(9.68)$ & $4 ; 06(.7)$ & $30(8.6)$ \\
\hline Age range in years & $24-47$ & $4-5 ; 09$ & $20.2(1.5)$ \\
\hline KBIT Matrices RS & $10(3.4)$ & $11.5(5.7)$ & $61.5(8.5)$ \\
\hline KBIT Matrices SS & $40(0)$ & $61.5(8.5)$ & - \\
\hline BPVS 2 RS & $36.4(12.8)$ & $59(10.42)$ & $142.4(24)$ \\
\hline BPVS 2 SS & $40(0)$ & $98.5(9.85)$ & $76(18.6)$ \\
\hline PPVT-III RS & - & - & $14(1.8)$ \\
\hline PPVT-III SS & - & - & $80.5(8.58)$ \\
\hline TROG-2 RS & $0.2(.45)$ & - & - \\
\hline TROG-2 SS & $55(0)$ & & -19 \\
\hline
\end{tabular}

RS=raw score; SS=standard score. KBIT: Kaufman Brief Intelligence Test. BPVS: British Picture Vocabulary Scales. PPVT: Peabody Picture Vocabulary Test, the American standardization of BPVS. TROG: Test for Reception of Grammar. For the group with DS, scores on standardized measures are available for 5 out of 6 participants. For the group with WS, scores are available for 5 out of 6 participants for PPVT, and for 4 out of 6 participants on the other measures.

\subsection{Method}

A two-choice picture selection task was used, created by Hirsch \& Wexler (2006), that involved three agentive/actional verbs (kiss, hold, push) and three psychological/experiencer verbs (remember, see, love), in the following experimental conditions: actional active (AA), e.g. Lisa kisses Bart; actional long passive (ALP), e.g. Bart was kissed by Lisa; actional short passive (ASP), e.g. Bart was kissed; psychological active (PA), e.g. Marge remembers Homer; psychological

2 Two nineteen-year-olds with WS participated in the study by Perovic \& Wexler (2006), while some of the TD controls' data were used in Hirsch \& Wexler (2006) and Perovic \& Wexler (2010). 
long passive (PLP), e.g. Homer was remembered by Marge; and psychological short passive (PSP), e.g. Homer was remembered. All sentences were semantically reversible, involving pictures of cartoon characters familiar across ages and cultures. Each verb was used twice in each condition, with different agents and patients. With 6 items in each condition, and 6 experimental conditions, the total number of items was 36 .

The procedure involved asking the participants to point to one of the two pictures presented on a computer screen that matched the sentence uttered by the examiner. A detailed introduction to the characters and actions used in the pictures and four training items for which feedback was provided were given to each participant before the task was administered. Additional training was given for experimental items that involved thought bubbles depicting experiencer verbs, remember and love (e.g. the stimuli for Marge remembers Homer, involved a picture of Marge, with a thought bubble containing a picture of Homer, above her head). The sentences were randomized automatically for each participant. Ten neurotypical adults, aged 19-35 (not included in the study), were tested on the task, showing a $100 \%$ performance.

\section{Results}

Our participants' responses (correct or incorrect) were analyzed using GLMM, a logistic regression model known to be better suited to binomially distributed data than standard ANOVAs (Jaeger, 2008). The fixed effects built into the model were Group (DS, WS, TD), Sentence Type (AA, ASP, ALP, PA, PSP, PLP), and Group $x$ Sentence Type interaction. Participants were treated as random effects by this model.

We obtained a highly significant effect of Group: $F(2,90)=26.261, \mathrm{p}<.001$, a significant effect of Sentence Type: $F(5,90)=3.589, \mathrm{p}=.005$, and a significant Group ${ }^{\star}$ Sentence Type interaction: $F(10,90)=2.430, \mathrm{p}=.013$.

The overall performance of the WS group, with an estimated probability correct of .88, was not statistically significantly different to that of the TD group's estimated probability correct of $.81(\mathrm{t}(90)=1.369, \mathrm{p}=.174)$. Planned posthoc Sidak-corrected comparisons revealed no statistically significant differences between the TD and WS groups on any of the sentence types (see Table 2). Both groups showed confident performance on actives of actional (AA) and psychological (PA) verbs, as well as passives of actional verbs, short (ASP) and long (ALP). Their performance on long and short passives of psychological verbs (PLP and PSP) was considerably lower, though: in the TD groups it seems no better than chance, with estimated mean probabilities correct at .50 and .53 , respectively. While the WS groups showed a higher performance on PLP (.67) and PSP (.75) than the TD group, these differences were not statistically significant. 
Participants with DS performed exceptionally poorly: their estimated mean probability correct for all sentences collapsed was only .46, significantly lower than that of the TD controls $((\mathrm{t}(90)=5.974, \mathrm{p}<.001)$, and significantly lower than that of the WS participants $(\mathrm{t}(90)=7.822, \mathrm{p}<.001)$. Crucially, these participants performed poorly even on the active sentences of actional verbs (AA), with estimated mean probability correct at .39, as well as on active sentences of psychological verbs (PA), with estimated mean probability correct at .42. Planned posthoc Sidak-corrected comparisons revealed that their performance on all sentence types, except for PLP and PSP, was statistically significantly lower than that observed in the TD and WS groups: at $\mathrm{p}<.001$ for AA and PA compared to both WS and TD, at $\mathrm{p}=.001$ for ASP compared to both WS and TD, at $\mathrm{p}<.001$ at ALP compared to WS, and $\mathrm{p}=.002$ compared to TD.

Table 2. Estimated mean probabilities correct (standard error) for each sentence type.

\begin{tabular}{|l|r|r|r|}
\hline \multicolumn{1}{|c|}{ Group } & DS & \multicolumn{1}{c|}{ TD } & WS \\
\hline AA & $.39(.09)$ & $.94(.04)$ & $.94(.04)$ \\
\hline ALP & $.42(.09)$ & $.83(.07)$ & $.89(.06)$ \\
\hline ASP & $.44(.11)$ & $.92(.06)$ & $.92(.06)$ \\
\hline PA & $.42(.09)$ & $.86(.07)$ & $.94(.04)$ \\
\hline PLP & $.56(.09)$ & $.50(.09)$ & $.67(.09)$ \\
\hline PSP & $.53(.15)$ & $.53(.15)$ & $.75(.13)$ \\
\hline
\end{tabular}

AA: Actional Active; ALP: Actional Long Passive; ASP: Actional Short Passive; PA: Psychological Passive; PLP: Psychological Long Passive.

\subsection{Individual differences}

Individual variation between participants was present in the TD and WS groups, but not in the DS group. Four participants with WS showed good performance on all passives, including psychological passives: three participants reached 5 or 6 out of the possible 6 correct on all passives, and one participant reached 4 out of 6 on PLP and 6/6 on PSP. The two remaining participants with WS, the youngest (aged 19) and the oldest (aged 43), reached scores that were especially low on PLP and PSP, just like the younger TD children. In the TD group, only one 5 -year-old showed near perfect performance; the remaining children showed a more varied range of scores, with the poorest scores on PLP and PSP. In the group with DS, no variation could be observed - there were no participants who showed a confident performance on any of the sentence types, with all participants performing at chance. 


\section{Discussion}

The results of our small-scale study reveal distinct patterns of performance in adults with IDs and TD controls on the different types of passive constructions tested here: the strongest performance was observed in adults with WS, and the poorest performance was observed in the adults with DS. This pattern is in line with previously reviewed literature; however, this is the first study to show an extremely low performance of adults with DS even on the simple Subject-Verb-Object (SVO) sentences, such as actives of actional verbs. We discuss our data in more detail below and discuss possible accounts of the observed patterns, linking the extremely poor performance of adults with DS with the possibility of cognitive decline associated with premature aging.

Adults with WS showed the highest performance, although it was not statistically significantly different from that of the TD control children. Looking at passives individually, we observe that on passives of actional verbs, short and long, both TD controls and WS adults reached a near-ceiling performance. The weakest performance of the TD and WS groups was on passives of psychological verbs, long and short. This is in line with numerous studies in the literature on typical development, as well as with results of children and teenagers with WS in Perovic \& Wexler (2010). The TD participants in the current study are aged 4-5;09 - the age before passives are fully mastered. It is expected that within the next year or two, these children will reach adult-like competence, just like the 7 -year-olds in Hirsch \& Wexler (2006). However, the patterns observed in the data of our WS group have not previously been reported: passive comprehension demonstrated by our adult group with WS is in fact much better than what is reported in the literature. Children and teenagers with WS in Perovic \& Wexler (2010) showed an extremely poor performance on both long and short passives of psychological verbs: only .18 proportion correct for PLP, and .33 proportion correct for PSP. These are considerably lower than the estimated mean probabilities correct of our sample of adults in the current study, .67 and .75 estimated probability correct for PLP and PSP, respectively. This result is driven by an excellent performance of four out of six adults in our sample who reached 5/6 or $6 / 6$ correct (and $4 / 6$ on one occasion for one participant) on passives of psychological verbs, the test case of mastery of the passive. This could not be due to the overall better intellectual abilities of our participants, as their standard scores on the test of non-verbal reasoning (KBIT Matrices), ranged between 61 and 70 (cf. the mean of 74 on this measure for participants in Perovic \& Wexler, 2010). It is possible that their background language skills were somewhat better developed, however. Note that our participants' ${ }^{3}$ receptive grammar standard scores

3 Note that we have no data for one of the participants with WS on any of the standardized measures; this participant, aged 31, scored 6/6 on every sentence type. 
(on TROG 2) were 76, 85 and 90, and receptive vocabulary standard scores (on PPVT III) were $81,83,88$. A similar spread of scores on these same measures is observed in the 5 teenagers in Perovic \& Wexler (2010), mentioned earlier, who also showed a strong performance on both types of passives. Still, it is difficult to make comparisons based on data from our very small sample of participants, especially keeping in mind the wide variation in language and intellectual skills in WS. Notice that even within our own "poor" performers on psychological passives, one participant's vocabulary standard score was 85 (in the low average range) and the other's was 43 (in the severely impaired range).

However, a factor that could be relevant is the chronological age of our participants with WS. Unlike in previous studies, our participants were all adults. Significant differences in the profiles of younger compared to older individuals with WS have been noted in the literature, with older individuals performing better (Bellugi et al, 1990; Brock, Jarrold, Farran, Laws \& Riby, 2007), which could be a result of the verbal abilities developing faster than non-verbal abilities in this population (Jarrold, Baddeley \& Hewes, 1998). Could we interpret the better performance on passives in adulthood as evidence of a more continuous language development in WS? It is impossible to reach such a conclusion on the basis of the data from our small sample of participants, and without recourse to longitudinal data, but it is an interesting idea to explore in the future, in larger samples, and longitudinally. It is also possible that the individual variation observed here is linked to a slightly different genetic makeup for different individuals with WS. After all, with a syndrome caused by the deletion of so many genes, we might expect differential effects of the size of the deletion on the cognitive but also the linguistic phenotype of WS.

The results of our group with DS are even more surprising: these participants showed a performance that was no different from chance, on every one of the 6 experimental conditions, including actives of both actional and psychological verbs. Recall that the same materials and the same active sentences used in our study, of the simple SVO type such as Marge kisses Homer, were successfully comprehended by more than 100 TD children aged from 3 years onwards in Hirsch \& Wexler (2006), 48 children and adolescents with ASD, both low and high functioning, in Perovic, Modyanova \& Wexler (2013), as well as 26 children and teenagers with WS in Perovic \& Wexler (2010). Even more relevant is the relatively successful performance of participants with DS on actives in the studies reviewed earlier. ${ }^{4}$ Our own studies (Perovic, 2001; 2006; 2008) confirm that young adults with DS are able to comprehend simple SVO sentences that

4 The exception is Joffe \& Varlokosta (2007), whose 6- to14-year-olds with DS only showed chance performance on actional actives, at 55\%. This could be a task effect, though, considering that both the WS group and the TD control group also showed a relatively poor performance on actives. 
contain both proper names and pronouns in the position of subject or object in a sentence. What then could be the reason for the exceptionally poor performance of the participants with DS in the current study?

One obvious explanation would be that our participants have poor overall language and intellectual skills, as observed in their extremely low scores on the standardized measures of grammar, vocabulary, and non-verbal reasoning, significantly worse than the scores of the participants with WS. Their results on the standardized test of reception of grammar (TROG-2) are especially low, with only one participant obtaining a raw score of 1 (understanding 4 out of 4 sentences in one "block"), and the other 5 participants scoring 0 , i.e. not passing a single block. Note that, on the German version of TROG, poor performances were reported in most of the adults with DS in Witecy \& Penke (2017), with some participants scoring only 2 blocks correct. Witecy \& Penke (2017) also report difficulties even with simple sentences in some of their participants.

It could be that by pure chance we recruited participants who were all at extremely low levels of functioning. Although this is possible, it would be unusual to have absolutely no variation in a sample of a population that is known for wide individual differences. However, an interesting avenue to explore is the link between Alzheimer's dementia and DS. We know that individuals with DS are at an increased risk of Alzheimer's disease after the age of about 40 - the average age of our participants. We also know that there may be some overlap between the linguistic impairments found in typical individuals with Alzheimer's and those reported for individuals with DS. However, it has not been established whether the dementia presentation in DS is similar to that seen in typical individuals, in terms of either behavioral or cognitive outcomes (Zis \& Strydom, 2018). Little systematic research on the effects of Alzheimer's-type dementia on the language of individuals with DS exists, with results of most studies being inconclusive, as shown in our review earlier. Yet, based on the exceptionally poor performance of our participants on both the standardized tests and our experimental task, we would like to tentatively suggest that the poor comprehension of both active and passive sentences observed in this study is the result of age-related decline. Note, however, that it is impossible for us to determine whether it is specifically the decline in language or cognitive skills that are the result of Alzheimer's-type dementia that caused our participants to perform the way they did. It is important not to confound the lack of language skills with the inability to be tested: our participants may not have been able to understand the task demands and perform on any of the standardized or experimental tasks. Nevertheless, if it were the task demands that were responsible, we would still have to attribute the difficulties here to the effects of aging/Alzheimer's (see Burt et al, 1998). We leave the question to further research. 


\section{Summary and conclusions}

Our small-scale study is yet another attempt to chip away at the question of how linguistic deficits in individuals with IDs might be teased apart from the effects of overall intellectual impairment and general language delays as well as the effect of age on language in IDs. Cross-syndrome comparisons allow for more detailed descriptions of linguistic phenotypes in clinical populations, which are crucial both in helping us understand how language impairment manifests in different conditions and in shedding light on the age-old question of what comes first: language impairment or cognitive impairment.

The surprising patterns uncovered in the linguistic competence of adults with DS and with WS in this study suggest that the decline associated with accelerated aging could be an important factor that hinders linguistic abilities in individuals with DS, while aging may have beneficial effects for at least some individuals with WS. More comprehensive studies are of course needed before we are able to reach any definitive conclusions. Future research should include large numbers of participants who would be tested on a range of standardized linguistic and cognitive assessments, in addition to experimental tasks aiming to gauge different aspects of their linguistic abilities. Cross-sectional studies should focus on participants of different ages (under 40 and over 40), while longitudinal studies should begin around the age of 30 . In turn, when ascertaining the effects of Alzheimer's dementia in adults with DS, it is crucial that researchers include assessments of linguistic functioning, because the decline in both cognitive and linguistic skills will affect these people's adaptive functioning in their everyday lives.

\section{Acknowledgments}

This research was supported by grants from the Anne and Paul Marcus Family Foundation to the Brain Development and Disorders Project, Massachusetts Institute of Technology, and from Choice Support, London, UK, to Alexandra Perovic. We would like to thank all the participants and their families, the Williams Syndrome Association (WSA) in the US, the UK charity Choice Support, Thomas Doukas, Christopher Hirsch, Nadya Modyanova, and all the students at the Wexler Lab for help with collecting data. The data on DS were presented by Thomas Doukas and Alexandra Perovic at the $15^{\text {th }}$ World Congress of the International Association for the Scientific Study of Intellectual and Developmental Disabilities in Melbourne, Australia, in August 2016. 


\section{References}

AAIDD (American Association on Intellectual Developmental Disabilities). (2010). Intellectual disability: Definition, classification, and systems of supports. Washington, DC.

Altmann, L. (2004). Constrained sentence production in probable Alzheimer disease. Applied Psycholinguistics, 25, 145-173.

Altmann, L., \& McClung, J. (2008). Effects of semantic impairment on language use in Alzheimer's disease. Seminars in Speech and Language, 29(1), 18-31.

Altmann, L., Kempler, D., \& Anderson, E. (2001). Speech production in Alzheimer's disease: Reevaluating morphosyntactic preservation. Journal of Speech, Language and Hearing Research, 44, 1069-1082.

Abbeduto, L., Warren, S, \& Conners, F. (2007). Language development in Down syndrome: From the prelinguistic period to the acquisition of literacy. Mental Retardation and Developmental Disabilities Research Reviews, 13(3), 247-261.

Bates, E., Marchman, V., Harris, C., Wulfeck, B., \& Kritchevski, M. (1995). Production of complex syntax in normal aging and Alzheimer's disease. Language and Cognitive Processes, 10, 487-539.

Bellugi, U., Marks, S., Bihrle, A., \& Sabo, H. (1988). Dissociation between language and cognitive functions in Williams syndrome. In D. Bishop \& K. Mogford (Eds.), Language development in exceptional circumstances (pp. 177-189). Hillsdale, NJ: Erlbaum.

Bellugi, U., Bihrle, A., Jernigan, T., Trauner, D., \& Doherty, S. (1990). Neuropsychological, neurological and neuroanatomical profile of Williams syndrome. American Journal of Medical Genetics, 6, 115-125.

Bittles, A., Bower, C., Hussain, R., \& Glasson, E. (2007). The four ages of Down syndrome. European Journal of Public Health, 17, 221-225.

Bridges, J., \& Smith, J. (1984). Syntactic comprehension in Down's syndrome children. British Journal of Psychology, 75, 187-196.

Borer, H., \& Wexler, K. (1987). The maturation of syntax. In Roeper, T., \& Williams, E. (Eds.), Parameter setting (pp. 123-172). Dordrecht, Germany: Reidel.

Brock, J, Jarrold, C., Farran, E., Laws, G., \& Riby, D. (2007). Do children with Williams syndrome really have good vocabulary knowledge? Methods for comparing cognitive and linguistic abilities in developmental disorders. Clinical Linguistics \& Phonetics, 21(9), 673-688.

Burt, D., Loveland, K., Primeaux-Hart, S., Chen, Y., Phillips, N., Cleveland, L., Lewis, K., Lesser, J., \& Cummings, E. (1998). Dementia in adults with Down syndrome: Diagnostic challenges. American Journal of Mental Retardation, 103, 130-145.

Carter-Young, E., \& Kramer, B. M. (1991).Characteristics of age-related language decline in adults with Down's syndrome. Mental Retardation, 29, 75-79.

Chapman, R., Seung, H-K., Schwartz, R., \& Kay-Raining Bird, E. (1998). Language skills of children and adolescents with Down syndrome: II. Production deficits. Journal of Speech, Language and Hearing Research, 41, 861-873.

Christodoulou, C. (2015). Morphosyntactic illusions in Down syndrome: The role of phonetics/phonology. Proceedings of the 39th annual Boston University Conference on Language Development, 7-9 of November, Boston. 
Christodoulou, C., \& Wexler, K (2016). The morphosyntactic development of case in Down syndrome. Lingua, 184, 25-52.

Clahsen, H., \& Almazan, M. (1998). Syntax and morphology in Williams syndrome. Cognition, 68, 167-198.

Devenny, D. A., \& Krinsky-McHale, S. J. (1998). Age-associated differences in cognitive abilities in adults with Down syndrome. Topics in Geriatric Rehabilitation, 13, 65-72.

Eriks-Brophy, A., Goodluck, H., \& Stojanovic, D. (2004). Comprehension and production of syntax in high-functioning individuals with Down syndrome. In Junker, M. O., McGinnis, M., \& Roberge, Y. (Eds.), Proceedings of the Annual Conference of the Canadian Linguistic Association. http://homes.chass.utoronto.ca/ cla-acl/actes2004/ EriksBrophy-Goodluck-Stojanovic-CLA-2004.pdf

Ewart, A. K., Morris, C. A., Atkinson, D., Jin, W., Sternes, K., Spallone, P., \& Keating, M. T. (1993). Hemizygosity at the elastin locus in a developmental disorder, Williams syndrome. Nature Genetics, 5, 11-16.

Fowler, A., Gelman, R., \& Gleitman, L. (1994). The course of language learning in children with Down syndrome. In H. Tager-Flusberg (Ed.), Constraints on Language Acquisition: Studies of Atypical Children. Psychology Press, Taylor \& Francis.

Hirsch, C., \& Wexler, K. (2006). Children's passives and their resulting interpretation. In K. U. Deen, J. Nomura, B. Schulz, \& B. D. Schwartz (Eds.), The Proceedings of the Inaugural Conference on Generative Approaches to Language Acquisition-North America, Honolulu, HI (University of Connecticut Occasional Papers in Linguistics, vol. 4, 125-136). Storrs, CT: University of Connecticut.

Iacono, T., Torr, J., \& Wong, H. Y. (2010). Relationships amongst age, language and related skills in adults with Down syndrome. Research in Developmental Disabilities, 31(2), 568-576.

Jarrold, C., Baddeley, A., \& Hewes, A. (1998). Verbal and nonverbal abilities in the Williams syndrome phenotype: Evidence for diverging developmental trajectories. The Journal of Child Psychology and Psychiatry, 39, 511-523.

Jaeger, T. F. (2008). Categorical data analysis: Away from ANOVAs (transformation or not) and towards logit mixed models. Journal of Memory and Language, 59, 434-446.

Joffe, V., \& Varlokosta, S. (2007). Patterns of syntactic development in children with Williams syndrome and Down's syndrome: Evidence from passives and wh-questions. Clinical Linguistics and Phonetics, 21(9),705-27.

Karmiloff-Smith, A., Al-Janabi, T., D’Souza, H., et al. (2016). The importance of understanding individual differences in Down syndrome. F1000 Research, 5, 389.

Karmiloff-Smith, A., Tyler, L., Voice, K., Sims, K., Udwin, O., Howlin, P., \& Davies, M. (1998). Linguistic dissociations in Williams syndrome: Evaluating receptive syntax in online and off-line tasks. Neuropsychologia, 36, 343-351.

Kavé, G. (2003). Morphology in picture descriptions provided by persons with Alzheimer's disease. Journal of Speech, Language, and Hearing Research, 46, 341-352.

Lott, I., \& Dierssen M. (2010). Cognitive deficits and associated neurological complications in individuals with Down's syndrome. The Lancet. Neurology, 9, 623-633. 
Malamud, N. (1972). Neuropathology of organic brain syndromes associated with aging. In C. M. Gaitz (Ed.), Aging and the brain (Advances in Behavioral Biology, vol. 3, pp. 63-87). New York: Plenum Press.

Maratsos, M., Fox, D. E. C., Becker, J. A., \& Chalkley, M. A. (1985). Semantic restrictions on children's passives. Cognition, 19, 167-191.

Mervis, C. B. (2006). Language abilities in Williams-Beuren syndrome. In C. Morris, H. Lenhoff, \& P. Wang (Eds.), Williams-Beuren syndrome: Research, evaluation and treatment (pp. 159-207). Baltimore, MD: Johns Hopkins University Press.

Nelson, L., Orme, D., Osann, K., \& Lott, I. T. (2001). Neurological changes and emotional functioning in adults with Down syndrome. Journal of Intellectual Disability Research, 45, 450-456.

Perovic, A. (2001). Binding principles in Down syndrome. UCL Working Papers in Linguistics, 13, 425-446.

Perovic, A. (2006). Syntactic deficit in Down syndrome: More evidence for the modular organization of language. Lingua, 116(10), 1616-1630.

Perovic, A. (2008). A crosslinguistic analysis of binding in Down syndrome. In Guijarro-P. Fuentes, M. Larranaga, \& J. Clibben. (Eds.), First language acquisition of morphology and syntax: Perspectives across languages and learners (Language Acquisition and Language Disorders vol. 45, pp. 235-267). Amsterdam: John Benjamins Publishing Company.

Perovic, A., \& Wexler, K. (2006). Knowledge of binding, raising and passives in Williams syndrome. In K. U. Deen, J. Nomura, B. Schulz, \& B. D. Schwartz (Eds.), Proceedings of the Inaugural Conference on Generative Approaches to Language Acquisition-North America, Honolulu, HI (University of Connecticut Occasional Papers in Linguistics, vol. 4, pp. 273-284). Storrs, CT: University of Connecticut.

Perovic, A., \& Wexler, K. (2007). Complex grammar in Williams syndrome. Clinical Linguistics and Phonetics, 21(9), 729-745.

Perovic, A., \& Wexler K. (2010). Development of verbal passive in Williams syndrome. Journal of Speech, Language, and Hearing Research, 53(5), 1294-1306.

Perovic, A., Modyanova, N., \& Wexler, K. (2013). Comparison of grammar in neurodevelopmental disorders: The case of binding in Williams syndrome and autism with and without language impairment. Language Acquisition, 20(2), 133-154.

Perovic, A., \& Wexler, K. (2018). Teasing apart explanations of a developmental delay in binding: experimental evidence from the comparison of SLI and Williams syndrome. Language Acquisition, 25, 24-38.

Ring, M., \& Clahsen, H. (2005). Distinct patterns of language impairment in Down syndrome, Williams syndrome and SLI: The case of syntactic chains. Journal of Neurolinguistics, 19, 479-501.

Rochon, E., Waters, G., \& Caplan, D. (2000). The relationship between measures of working measure and sentence comprehension in patients with Alzheimer's disease. Journal of Speech, Language and Hearing Research, 43, 395-413.

Rondal, J. A., \& Comblain, A. (1996). Language in adults with Down syndrome. Down Syndrome Research and Practice, 4(1), 3-14. 
Royston, R., Waite, J., \& Howlin, P. (2019). Williams syndrome: recent advances in our understanding of cognitive, social and psychological functioning. Current Opinion in Psychiatry, 32(2), 60-66.

Sanoudaki, I., \& Varlokosta, S. (2015). Pronoun comprehension in individuals with Down syndrome: The role of age. International Journal of Language \& Communication Disorders, 50(2), 176-186.

Schaner-Wolles, C. (2004). Spared domain specific cognitive capacities? Syntax and morphology in Williams syndrome and Down syndrome. In S. Bartke \& J. Siegmuller (Eds.), Williams syndrome across languages. (Language Acquisition and Language Disorders, vol. 36, 93-124). Amsterdam: John Benjamins Publishing Company.

Wexler, K. (2004). Theory of phasal development: Perfection in child grammar. MIT Working Papers in Linguistics, 48, 159-209.

Witecy, B., \& Penke, M. (2017). Language comprehension in children, adolescents and adults with Down syndrome. Research in Developmental Disabilities, 62, 184-196.

Zigman, W., \& Lott, I. (2007). Alzheimer's disease in Down syndrome: Neurobiology and risk. Mental Retardation and Developmental Disabilities Research Reviews, 13, 237-246.

Zis, P., \& Strydom, A. (2018) Clinical aspects and biomarkers of Alzheimer's disease in Down syndrome. Free Radical Biology and Medicine, 114, 3-9.

Zukowski, A. (2001). Uncovering grammatical competence in children with Williams syndrome. Unpublished doctoral dissertation, Boston University. 